\title{
A CMMS Expert using BIM for IBS Building Maintenance
}

\author{
Noraini Hamzah ${ }^{1}$, Zul-Atfi Ismail², Syahrul Nizam Kamaruzzaman ${ }^{3}$, Azrul A. Mutalib ${ }^{1}$ and Adi Irfan Che Ani ${ }^{4}$ \\ ${ }^{1}$ Department of Civil and Structural Engineering, Faculty of Engineering and Built Environment, Universiti Kebangsaan Malaysia, 43600 \\ Bangi, Selangor, Malaysia \\ ${ }^{2}$ School of Environmental Engineering, Kompleks Pusat Pengajian Jejawi 3, Universiti Malaysia Perlis, 02600 Arau, Perlis, Malaysia \\ ${ }^{3}$ Building Surveying Department, Faculty of Built Environment, University of Malaya, Mercu Alam Bina, Lembah Pantai, 50603 Kuala Lumpur \\ ${ }^{4}$ Department of Built Environment, Faculty of Engineering and Built Environment, Universiti Kebangsaan Malaysia, 43600 Bangi, Selangor, \\ Malaysia
}

\begin{abstract}
In the IBS building maintenance, the conventional methods to the project delivery and its failure to form effective communication channel between complementary knowledge on IBS construction and related members that is conducted in the sequential manner has resulted in ineffectiveness for managing building maintenance, where a paradigm shift within the IBS traditional approach is necessary. The research results described are concerned with i) an integrated system to record, diagnose and analyse information for IBS building maintenance to detect patent or latent defect, select an effective repair method, provide appropriate planning decision and reduce risks of defect throughout the building lifetime. ii) building a decision making support in diagnosis in IBS building maintenance based on robust data collection about concrete defects and causes including in the selection of a durable replacement design and material or the proper rehabilitation method. The system development was based on analysis of number of interviews and case studies conducted with professional engineers working in IBS building maintenance departments. The paper concludes that implementing a CMMS Expert using BIM can help improve the performance of IBS building design, construction and maintenance operations.
\end{abstract}

\section{Introduction}

Maintenance management is defined as the combination of all technical, administrative and management activities of the post-construction life cycle of a facility. These activities overview are concerned with the technical specifications (e.g. method of defect identification and assessment), administrative processes (e.g. maintenance plans and general execution) and management such as contract conditions, policy and maintenance strategy related issue. In addition, it considered the maintenance factors of labour skill, interpersonal relationship, maintenance performance, material quality control and investment control in order to support the sustainable maintenance of building facility [1]. Besides, it is the recursive process of coordination and collaboration (e.g. designer and site engineer) to provide the effective service delivery of building maintenance to perform building facilities long-lived and reduction of life cycle cost [2,3]. In general, maintenance management is considered as part of the construction sector for the larger service of post-construction activity and process. However, as IBS construction projects grow in scale and complexity, interconnections between the mentioned activities and processes can be noticed in a problematic maintenance management to monitor the defects for the corrective and preventive maintenance action [4,5]. The

\footnotetext{
a Corresponding author: zulatfippkas@gmail.com
}

management of maintenance in the complex and high-rise buildings claims a high emphasis on the systematic activity and process for the improvement of maintenance management system of IBS construction. Nevertheless, tool and technique in maintenance management are more significant than those in general maintenance management (post-construction activity and process) $[6,7]$. This highlights the importance of processes and activities with involved sophisticated tool and the efficient technique for improvements.

In the IBS building maintenance, the conventional methods to the project delivery and its failure to form effective communication channel between complementary knowledge on IBS construction and related members that is conducted in the sequential manner has resulted in ineffectiveness for managing building maintenance, where a paradigm shift within the IBS traditional approach is necessary [8,9]. Therefore, the need for sophisticated tools and efficient techniques using an appropriate Information and Communication Technology (ICT) (e.g. BIM and CMMS) for implementing an integrated approach in the design and construction could facilitate new maintenance management processes for IBS building projects in the future [6,7]. In the meanwhile, the most maintenance industry has been generally revolved around conventional method (e.g. MS Word and MS Excel) with limited uses 
of 3D models for visualisation and maintenance development [10]. Recently on IBS construction sites, there are many efforts to improve the efficiency of maintenance management activities through the use of more ICT-based systems (i.e. BIM). Modern developments in BIM technology related to construction industry has been used for facilitating maintenance on various activities (failure analysis, documentation of maintenance, fault location, repair and reconstruction). An example is the bottleneck of massive data between maintenance components and building management, which can now be eliminated by converting raw data on the quality of systems and the process capability in the information and knowledge for optimal maintenance strategies $[11,12,13]$. In addition, with the development of emerging technology such as BIM, maintenance management improvements in IBS building construction has become possible [14]. Several other industry projects worldwide, for example real estate, waste management, transportation, supply chain and facility management, have been successfully completed by implementing BIM technology $[15,16,17,18,19]$. BIM can assists clients to determine the appropriate technology strategy and scope of each deliverable, with the intention of reducing redundancy and rework while improving performance and productivity of an operation and maintenance processes effectively in the future [20,21,22]. Whereas BIM related studies mainly focus on utilising sophisticated tool and efficient technique, associating decision making support in diagnosis principles can help in achieving new levels of efficiency in IBS building maintenance performance.

The developed model of decision making support in diagnosis quantifies the overall condition properly and evaluates the possible alternatives regarding selecting a solution for building improvements [23]. A few researchers have considered IBS to provide more efficient decision support tools in diagnosis such as PPMOF (Prefabrication, Preassembly, Modularisation and Offsite Fabrication), IMMPREST (Interactive Method for Measuring PRE-assembly and Standardisation), PSSM (Prefabrication Strategy Selection Method), and CMSM (Construction Method Selection Model). Nevertheless, these existing tools consider inadequate aspects of sustainability [24]. Sustainability involves issues such as the design and management of buildings; materials performance; operation and maintenance; long-term monitoring; and the dissemination of knowledge in related technical contexts. Besides, most of the available decision making support in diagnosis guidelines and tools are only used after the design of the IBS building project is about to be completed [25]. Therefore, an application that utilises the intelligent objects of BIM to manage decision making support in diagnosis would provide better service delivery of IBS building maintenance. This paper proposes a CMMS Expert using BIM that not only facilitates the decision making support in diagnosis but also the ability to provide IBS component diagnosis integration for reducing risks of defect of an IBS building.

\section{System Component}

The proposed system "CMMS Expert using BIM" comprises three components: defect report and assessment, defect diagnosis as well as defect control. These components are accessible through a BIM model user-friendly interface. Software applications can be developed in different platforms including those of BIM model with the integration of CMMS and Expert System. Based on the findings of [22], a BIM-based platform was considered to be the most appropriate in development of the system. The conceptual design of a BIM-based platform is suitable for larger and more complex and high-rise buildings to support design consistency and visualisation, cost estimations, assessment and monitoring, retrofit planning, implementation of lean maintenance and improved construction team collaboration. [26] investigated the feasibility of tracking any potential defects and reworks using BIM-based platform in order to perform efficient operation and maintenance work, particularly in complex projects.

The defect report and assessment allows users to lodge report using the electronic facilities defect form with complete attributes in the database. The defect diagnosis is to present the user for selecting one of the three knowledge bases namely leaking, jointing and cracking in concrete including the selection of appropriate construction design or materials and repairs method recommendations. The defect control is to provide technology transfer of knowledge from designers to engineers and vice versa and it is a useful reference guide for a wide range of concrete defects risk leading to accurate analysis using design condition index. The adopted synthesis of good practices of maintenance operations in CMMS Expert using BIM is based on the findings of the interviews and case studies conducted with professional engineers working in IBS building maintenance departments [27]. This paper is part of a larger research and will only introduce and discuss the entire process of the system. This process is illustrated in the following sections.

\section{Maintenance Management Process}

The maintenance management processes are adopted into the maintenance management system (MMS) to improve the maintenance management practices at the IBS buildings. The knowledge transfer support is the new approach of this prototype system that is provided with the diagnosis of defects and decision making for structure component based on the inputs and information supplied by the user for handling the maintenance on the IBS building. Besides, the prototype system can be accessed through portable devices such as tablet and notebook at the site location with the database provided (e.g. VB.net and MS Access) for each defects and structure locations in the report assessment. The safety database is used to protect the data entry and design, construction as well as maintenance collection for the structures and facilities at the IBS buildings. The BIM can be integrated into the prototype system with the BIM platform provided (e.g. 
Autodesk Revit) for each knowledge feedback of the nature of defects components and their cause into the model that facilitate the assessment process in maintenance management. The data obtained in the case studies and literature review revealed that the IBS buildings are using the conventional method (paper-based reports/unsystematic database) in managing the maintenance activities for building structure and facility. This arise a problematic situation such as defects repetition (leaking, jointing and cracking) and less competent contractor that need sophisticated tools towards a solution. Presently, the implementation of ICT tools in the new system is the better improvement to lead the tremendous saving in budget, time planning and to analyse the precise data in handling the defect diagnosis and control. The integration of modern ICT tools such as BIM, CMMS and Expert System also facilitates the knowledge transfer for maintenance management processes in recommending the repair structure components needed for the efficacy of the maintenance management practices. From the case studies findings, the involved maintenance management processes are the maintenance identification (for defect report and assessment), defect and cause analysis (for defect diagnosis) and risk level analysis (for defect control) as the main stages in managing maintenance for IBS building structure and facility that described in Figure 1.

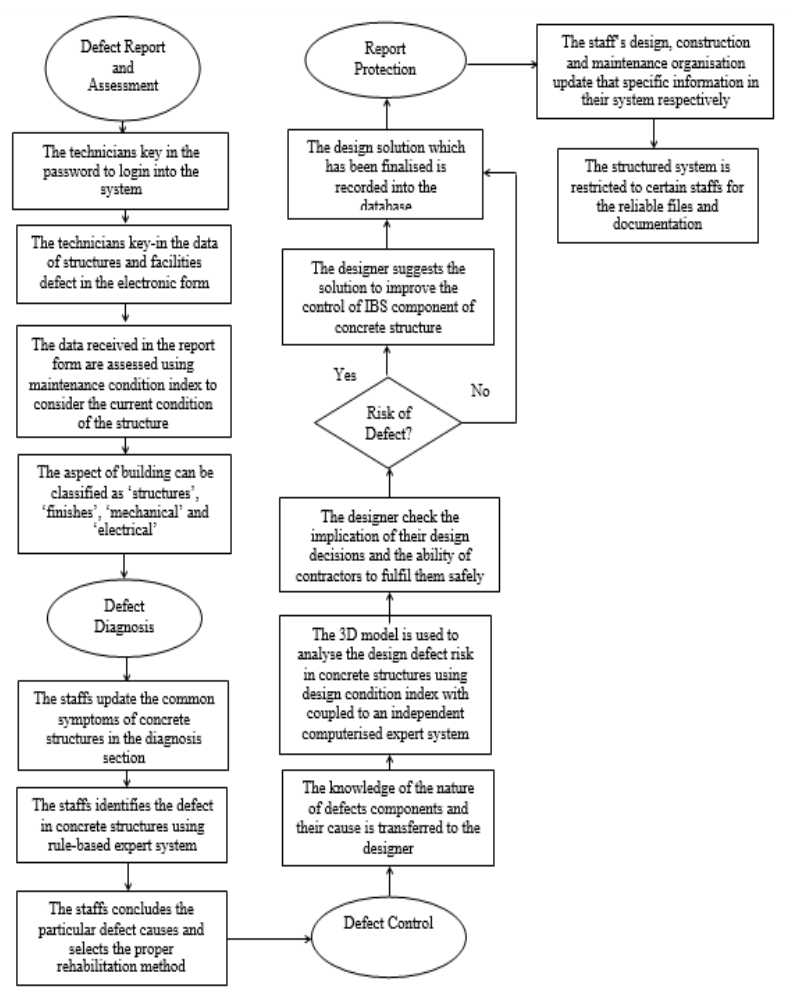

Figure 1. Maintenance Management Processes.

The defect report and assessment is the initial process where a technician will allege any defect component occurred in building. The defect inspection is undertaken to measure the defect performance on site and then this information will be put in the system for recorded after defect assessment value is determined. The database in the system is linked with the three software, namely, CMMS, Expert System and BIM model. The knowledge transfer can be utilised through this system when the knowledge of history for defect component from the defect report and assessment process is distributed to the engineer within same organisation. The engineer is assigned to screen each of defect component for diagnosis task in order to analyse the cause and reason of defect that ensued. The expert system can be used to examine the defect symptoms on each of component which are based on the knowledge obtained from literature searches, codes of practice, manuals, textbooks, technical reports, journals and conference proceedings, civil work reports and experienced concrete specialists. The knowledge of defect diagnosis in the expert system then is transferred to the designer in the BIM model for pursuing the design defect cause and reason and even to classify the risk level of defect component. Finally, the knowledge of design defect based on the materials specification and visual information of BIM model is transferred back to the engineer for work planning and maintenance execution. The knowledge transfer in this system will improve the defect diagnosis and decision making process for critical defect element based on the maintenance impact undertaken heading to sophisticated management and maintenance effectiveness.

\section{System Architecture}

The system architecture focuses on the collection of the structure and facility defect information for defect assessment, defect diagnosis and defect control as well as analyse the data for the execution reference in IBS building maintenance. The mobile devices such as laptop enable staff to compare and adapt the data at any facility location with the staff's report recorded in the prototype system user-interface (MS Visual Basic.NET). The staff will be able to capture the knowledge of the structure and facility defect, update about the detailing defect, and record the relevant aspect of the defect attribution into the electronic form of the system prototype. This knowledge is stored in a computer database central (MS Access) linked to the technician, engineer and designer at the maintenance organisation for further process. The information about the defect is assessed using maintenance condition index in Condition Rating Level (CRL) format for considering the current condition of the structure and its components, analysed for the maintenance defect diagnosis using the decision making process and assessed using the design condition index in Average Index Level (AIL) format for reducing the risk of design defects at the site location. The workflow is illustrated in Figure 2, 3 and 4. The 'CMMS Expert using BIM' can be divided into three main components, which are BIM, CMMS and Expert System. Each component plays a different role in the prototype system. The BIM technology is to enable the concrete structure component design defect analysis carried out by comparing concrete structure defects and causes on 3D model including record modelling in BIM database while the CMMS to 
capture knowledge of the defect report and assessment. The Expert System is to capture the knowledge of concrete defect diagnosis and in the selection of a durable replacement design and material or the proper rehabilitation method for the system.

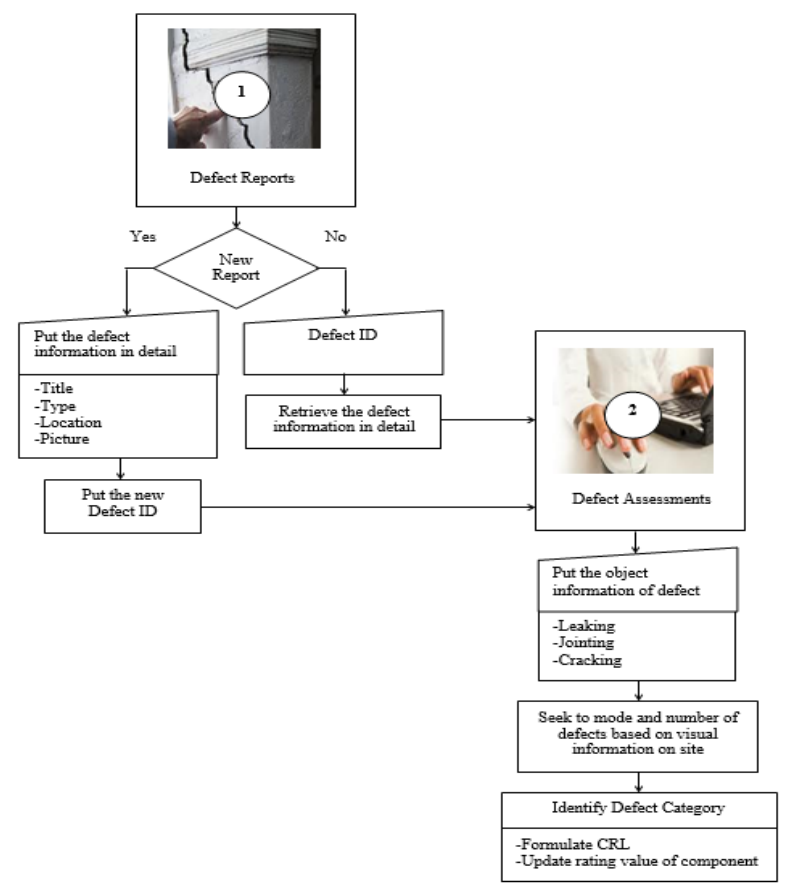

Figure 2. Defect Report and Assessment Process.

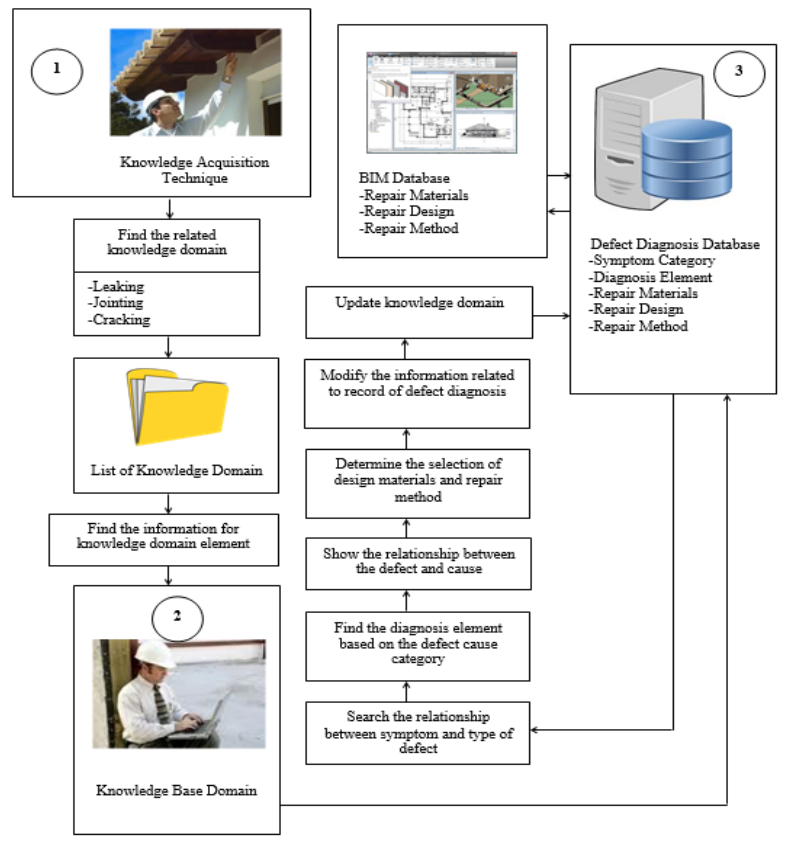

Figure 3. Defect Diagnosis Process.

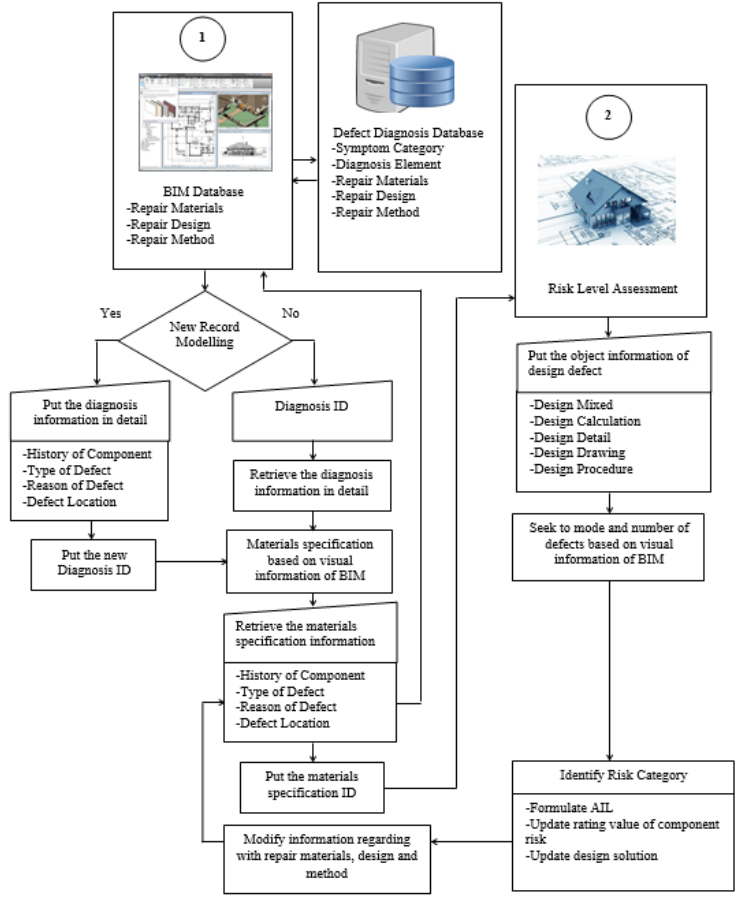

Figure 4. Defect Control Process.

\section{A CMMS Expert using BIM}

This section describes the interactive portion of the system including input data validation and updates of system database in the information system prototype. The prototype system has four main functions and graphical user interfaces:

i. System Login;

ii. Defect Report and Assessment;

iii. Defect Diagnosis; and

iv. Defect Control.

\section{System Login}

The prototype system starts when the main interface, namely, "CMMS Expert using BIM" is displayed (see Figure 5). The login menu in the form is operated via ID and password input in allowing user such as technician and engineer to enter the prototype system.

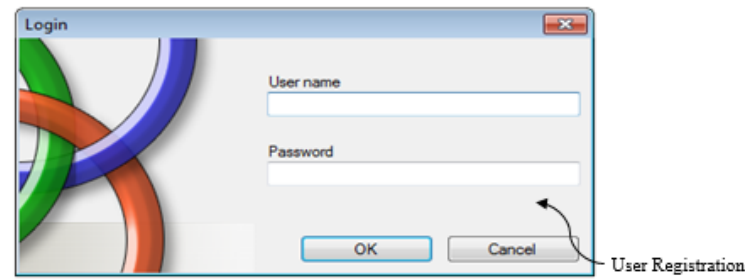

Figure 5. "CMMS Expert using BIM" Main Screen.

The users have to register their profile in order to report their defect, assess the current condition of the concerned building structure and undertake defect diagnosis. This user registration procedure and login application are shown in Figures 6 and 7 respectively. 


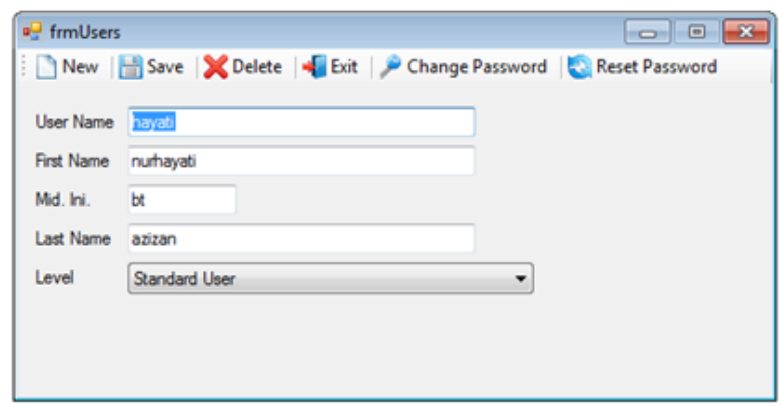

Figure 6. Technician/ Engineer-User Registration.

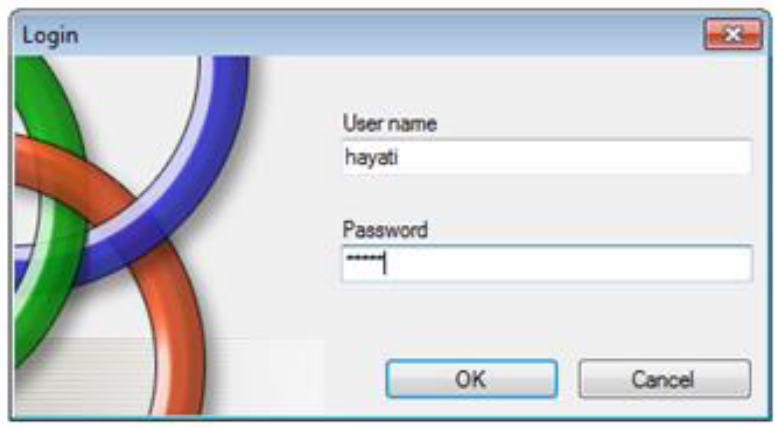

Figure 7. Technician/ Engineer-Login Application.

Defect Report and Assessment

After clicking on the Log in button, the user enters the 'Dash Board' form as shown in Figure 8.

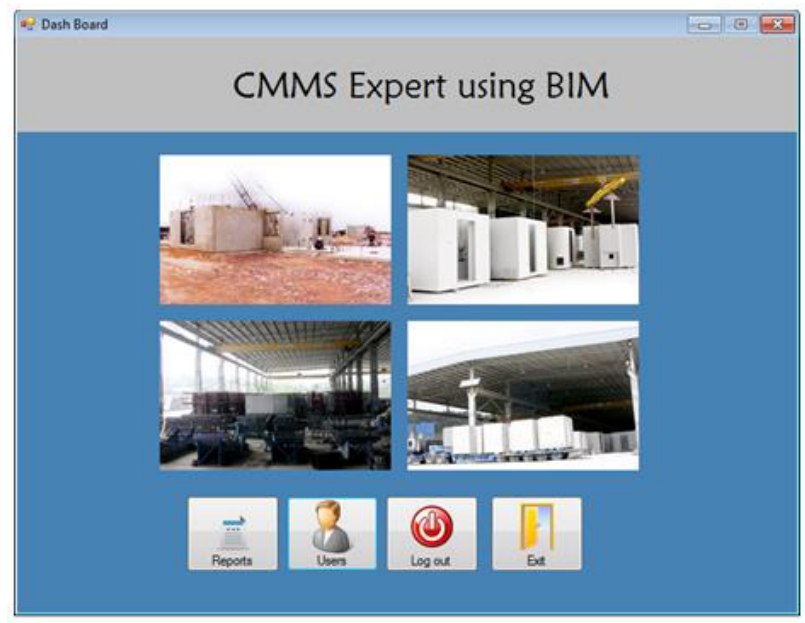

Figure 8. Technician/ Engineer-Main Form.

In this application form, the user is provided with two menus, namely, reports and users to access other forms in the application as shown in Figures 8. Figure 9 shows the report list data involved on building structure and facility defect:

- ID;

- Title;

- Date;

- Rating;

- Location

- Status; and

- Material Type.

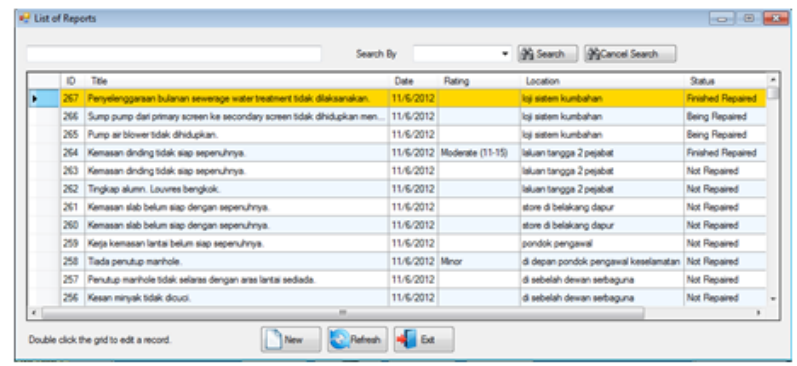

Figure 9. Technician-Report List.

Figure 10 shows that the new form will be displayed after clicking new report button. It shows the new report details form involved on building structure and facility defect:

- Title;

- Date;

- Location;

- Type;

- Picture;

- Maintenance Condition Index;

- Rating;

- Status;

- $\quad$ CRL; and

- Inspector.

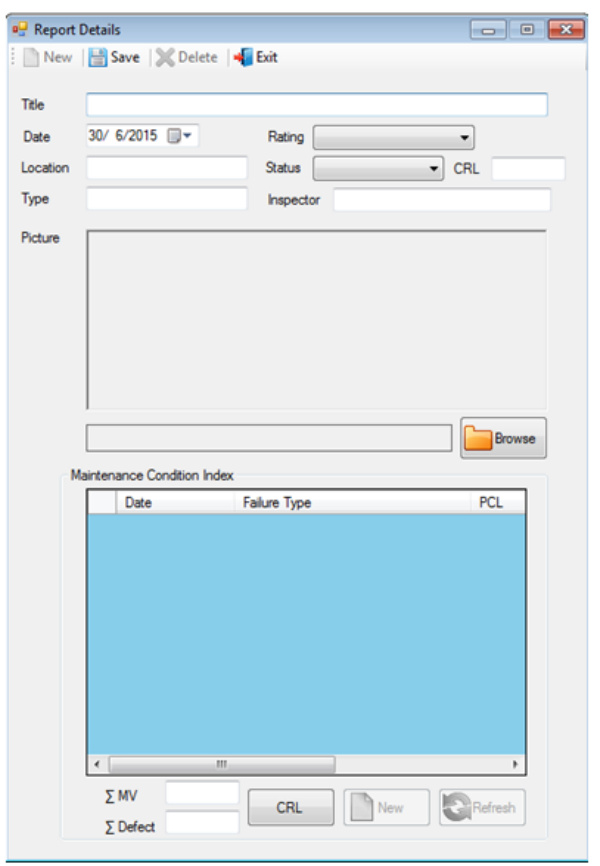

Figure 10. Technician-Report Form.

The user need to click the save button for the new report details form where its information is sent to the database system in storing defect report and assessment data for IBS building structure and facility (see Figure 11 and Figure 12). 


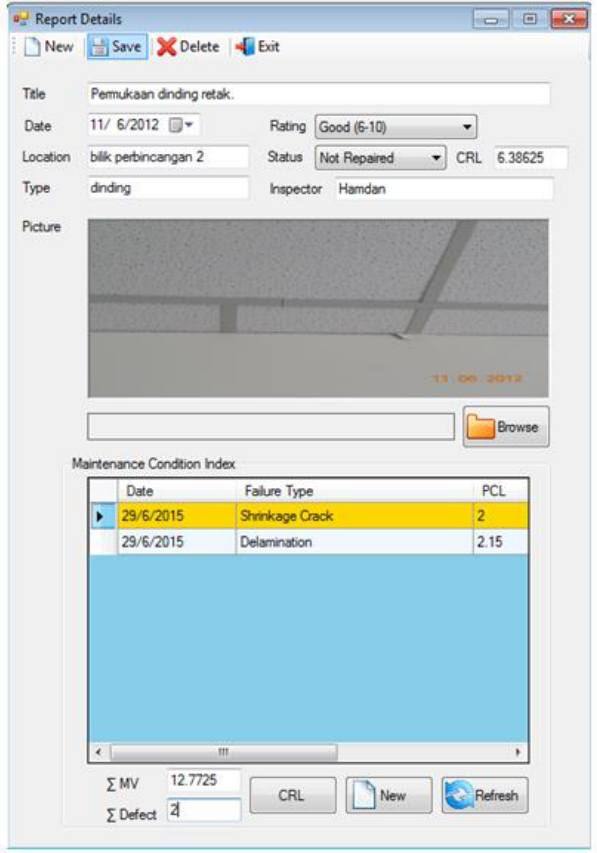

Figure 11. Technician-Save Form.

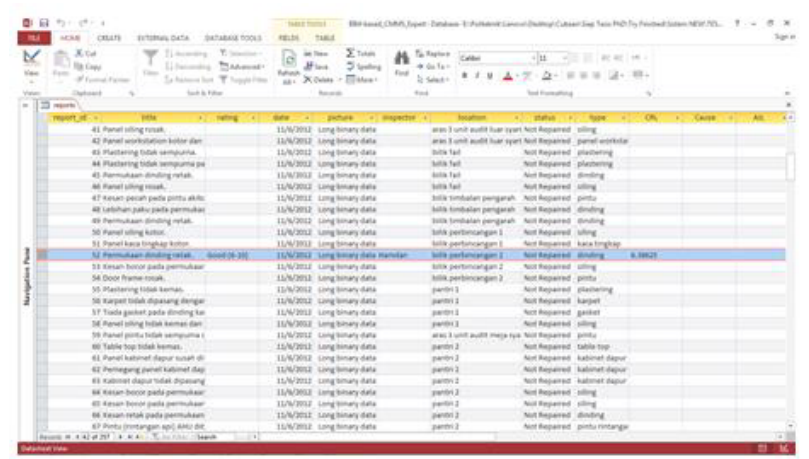

Figure 12. Technician-Save information into MS Access database.

\section{Defect Diagnosis}

Figure 13 shows the 'defect diagnosis' form. This form also provides the engineer with the additional data on 'cause', 'repairs design and material' and 'repairs method' button (see Figure 14 and Figure 15). The 'cause' functions in the 'defect diagnosis' forms allow the defect identification and needed diagnosis for the repair strategies recommendation. The concerned defect IBS component of concrete structure is identified based on the symptom setting and the defect only being diagnosed from the inputs and information supplied by the user after clicking the 'result' button at the right-side bottom of the form. Thus, the staff could address diagnostic-related issues and identification and repair or rehabilitation recommendations of IBS concrete structure which is undertaken at the site location effectively.

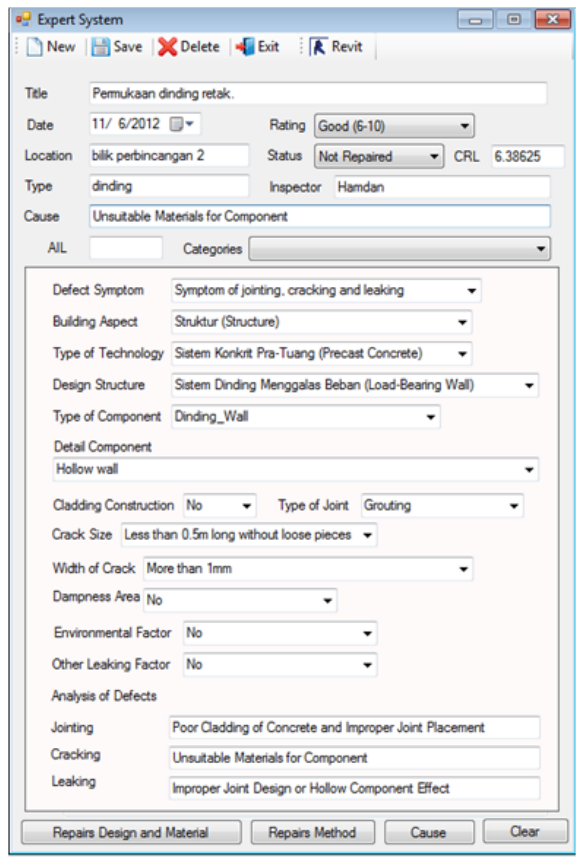

Figure 13. Engineer-Defect Diagnosis Form.

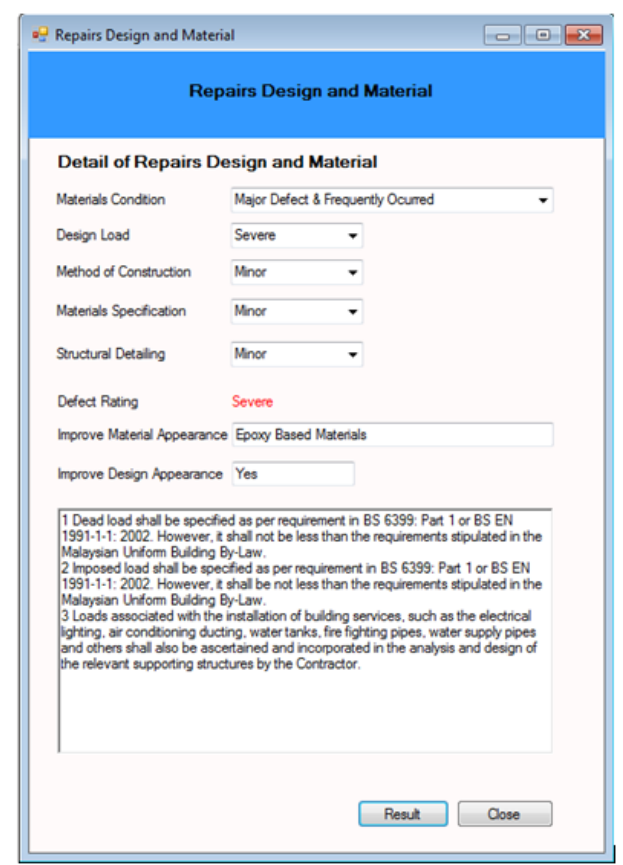

Figure 14. Engineer-Repair Materials and Design Form. 


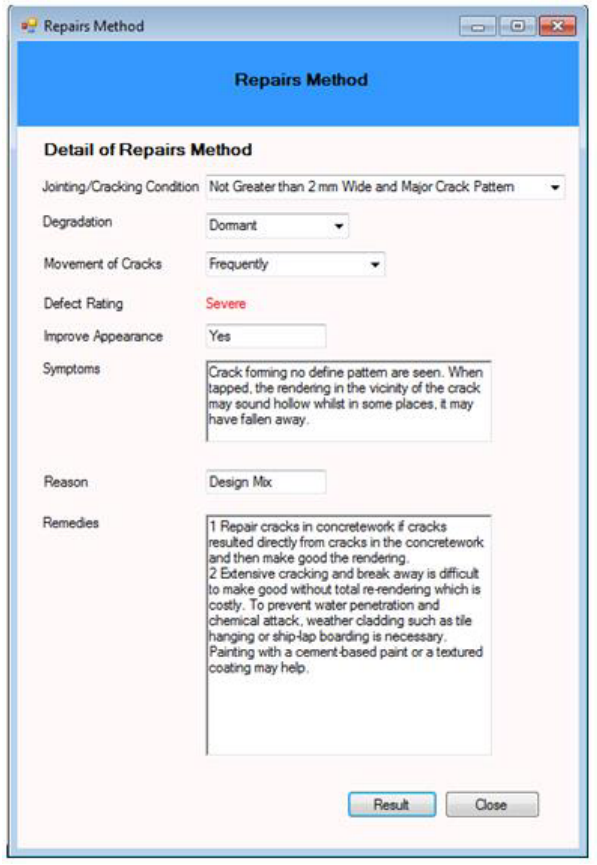

Figure 15. Engineer-Repair Method Form.

Figure 14 and 15 highlights the repair materials, design and method from the content of a 'Symptom of Leaking, Jointing and Cracking' analysis procedure based on the literature searches, codes of practice, manuals, textbooks, technical reports, journals and conference proceedings, civil work reports and experienced concrete specialists, which facilitates the engineer to evaluate the concrete structure information for the defect diagnosis. The result of defect diagnosis information being used to improve the performance and durability of concrete structures and is coupled to an independent BIM database management system (BIM) through Revit DB link for controlling risk of defects on design criteria for effective construction methods.

\section{Defect Control}

Figure 16-22 shows how the expert system database collaborated with BIM technology through knowledge transfer to perform specialised tasks, which provides the report analysis of defect diagnosis for particular IBS building components in determining an AIL. AIL numerically rates the condition of the design defect IBS concrete on a scale of 1 to 5 (Table 7) by evaluating each concrete design deficiency based on the 'Design Condition Index' form in Figure 22.

Table 1. The Average Index Level (AIL) for the Evaluation of Design Defect.

\begin{tabular}{|c|c|c|c|}
\hline $\begin{array}{c}\text { Rating } \\
\text { Scale }\end{array}$ & $\begin{array}{c}\text { Average Index } \\
\text { (a) }\end{array}$ & \multicolumn{2}{|c|}{ Categories } \\
\hline 1 & $1.00 \leq \mathrm{a} \leq 1.50$ & Ignorable & Does Not Affect \\
\hline 2 & $1.50 \leq \mathrm{a} \leq 2.50$ & Not Important & Slightly Affected \\
\hline 3 & $2.50 \leq \mathrm{a} \leq 3.50$ & Moderate & $\begin{array}{c}\text { Moderately } \\
\text { Affected }\end{array}$ \\
\hline 4 & $3.50 \leq \mathrm{a} \leq 4.50$ & Important & $\begin{array}{c}\text { Strongly } \\
\text { Affected }\end{array}$ \\
\hline 5 & $4.50 \leq \mathrm{a} \leq 5.00$ & $\begin{array}{c}\text { Very } \\
\text { Important }\end{array}$ & $\begin{array}{c}\text { Extremely } \\
\text { Affected }\end{array}$ \\
\hline
\end{tabular}

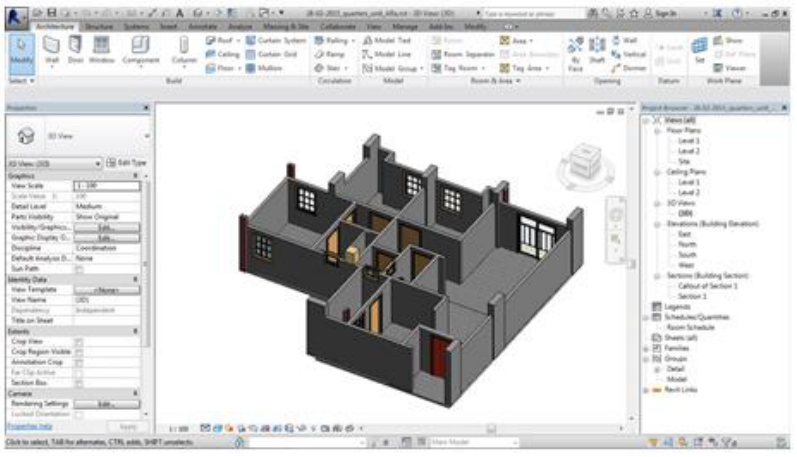

Figure 16. Designer-Floor Plan in 3D View.

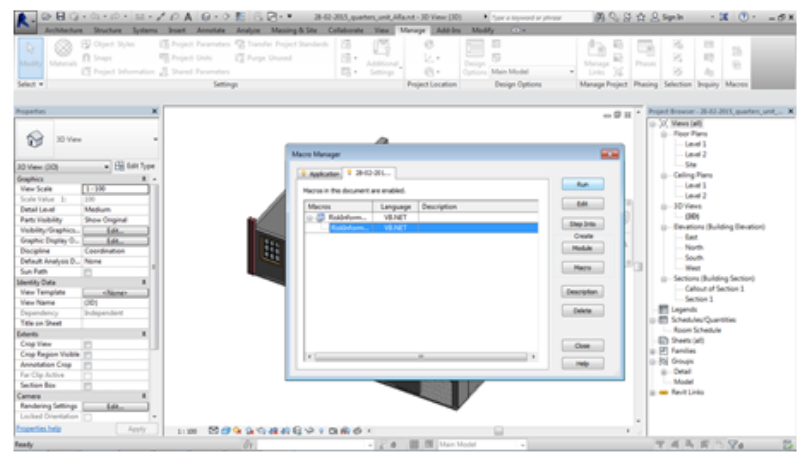

Figure 17. Designer-Start the Program Module in Revit API Application.

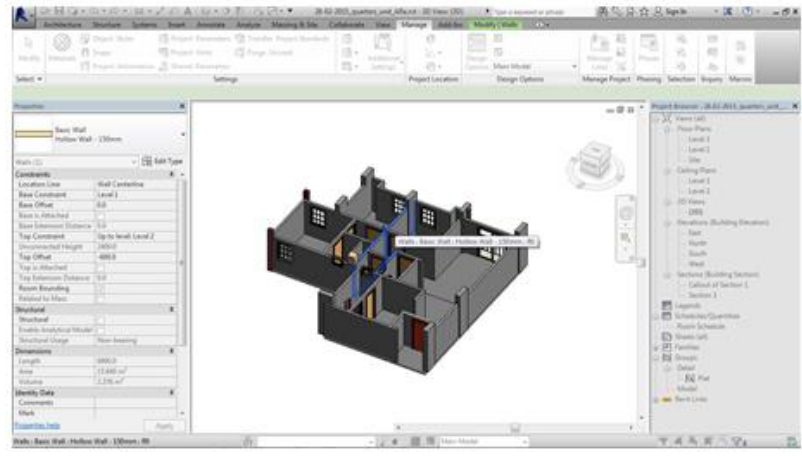

Figure 18. Designer-Wall Component is selected on 3D Floor Plan.

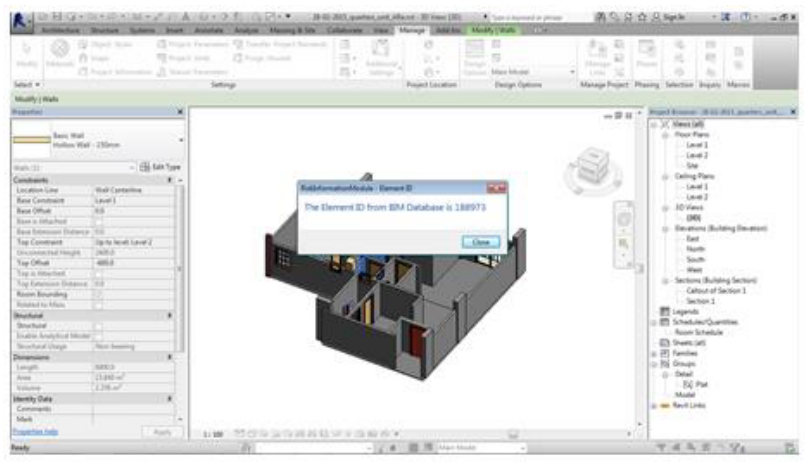

Figure 19. ID Element from Wall Component selected is showed on screen. 


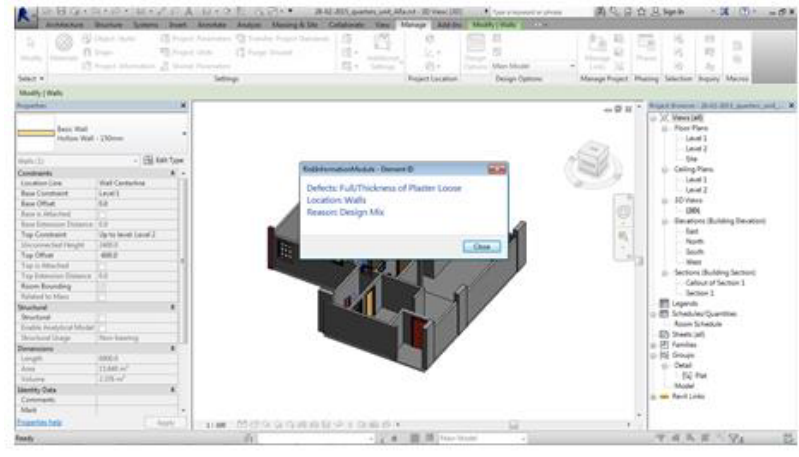

Figure 20. Maintenance Information based on the specific ID Element is captured from BIM database.

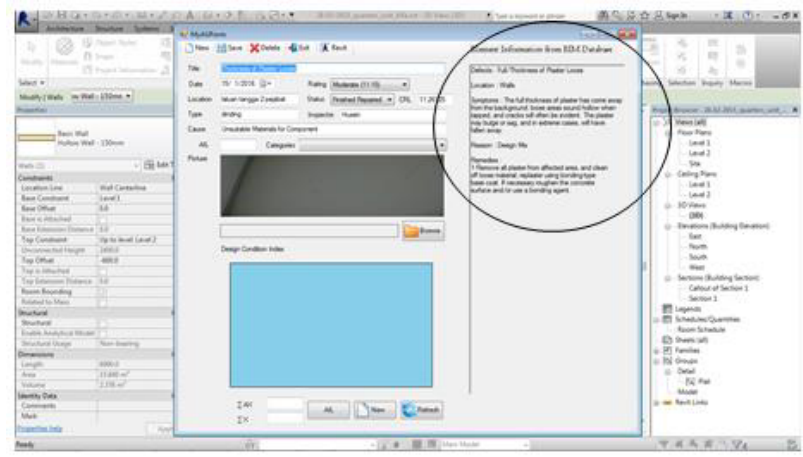

Figure 21. Design Condition Index Form from Wall Component selected is appears afterwards.

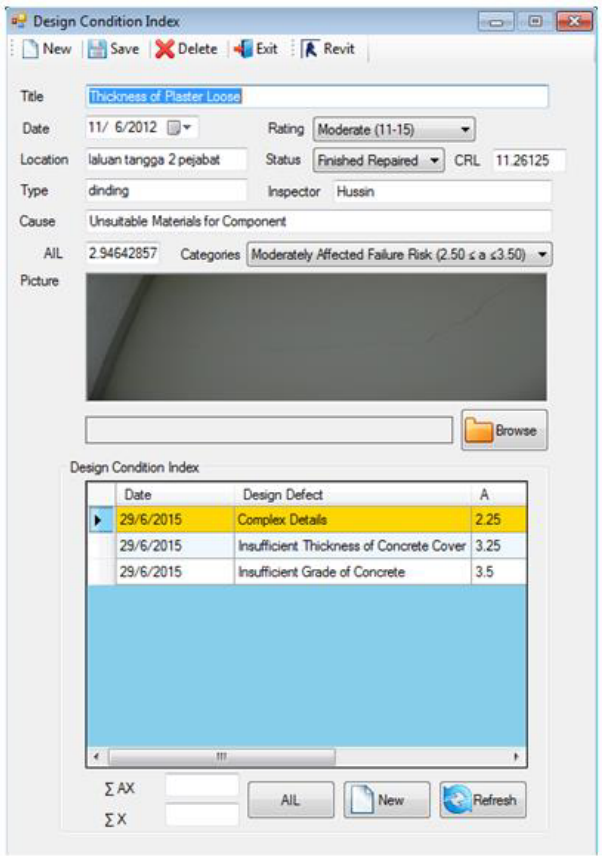

Figure 22. Designer-AIL Index Score that already calculated in the Design Condition Index Form is transferred back to engineer through database link.

BIM model database provides the record modelling for material properties and design procedures as well as source of engineer's knowledge of the defect, its cause and repair method for structure defects using 3D model with coupled to an independent computerised expert system through Revit DB link. The designer need to double click the IBS component in 3D view for the selected record modelling where its material, design and procedure details will be displayed in the BIM model in analysing design defect information such as design concrete mix, design calculations, design details, drawings and design procedures in concrete structure. For example, the IBS component item provides the record inventory in order to meet all necessary design defect information including source of engineer's knowledge needed as shown in Figure 23-25.

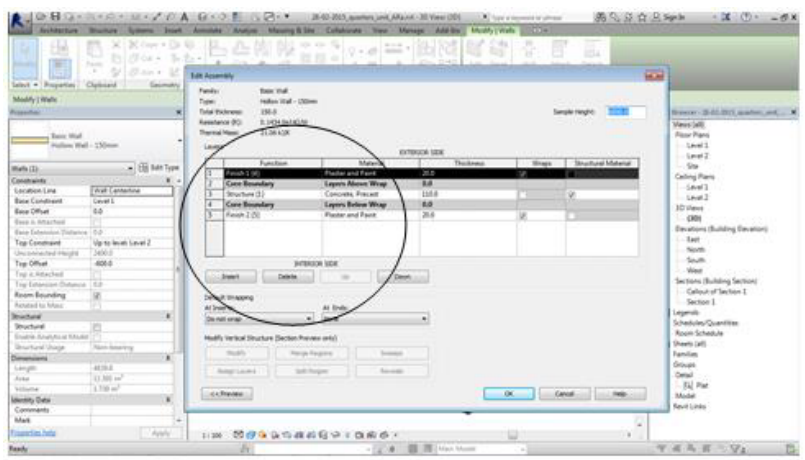

Figure 23. Material Properties and Design Procedures in BIM.

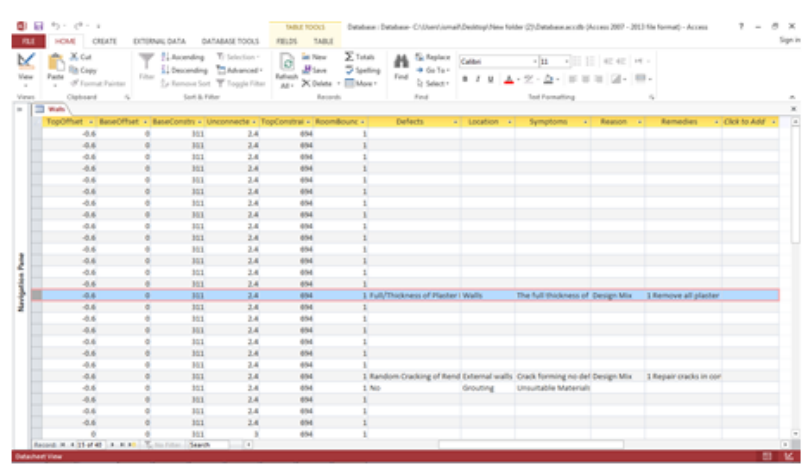

Figure 24. Source of Engineer's Knowledge from Computerised Expert System Database is transferred to BIM through Revit DB Link.

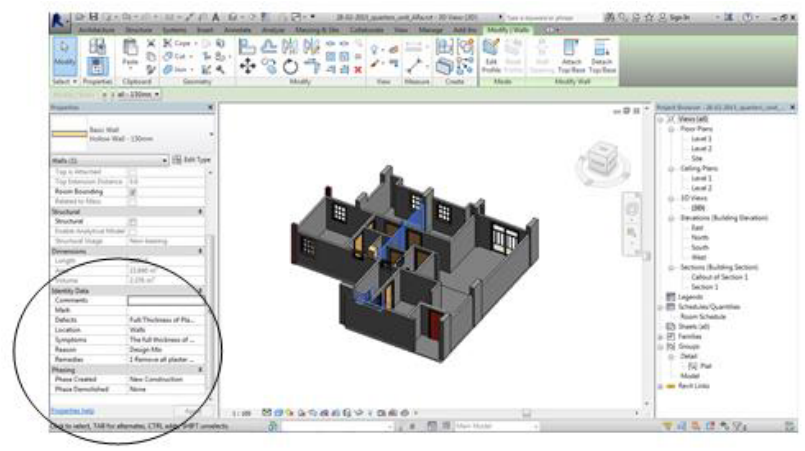

Figure 25. Source of Engineer's Knowledge in BIM that is used for Design Condition Index Form.

\section{Conclusion}

This paper presented a CMMS Expert using BIM to record, diagnose and analyse information of maintenance projects. A few conclusions can be drawn from the research: 
- The development of sophisticated tool and the efficient technique is an important issue in BIM technology for IBS building maintenance. Applying an adequate processes and activities with involved sophisticated tool and the efficient technique much facilitates creating decision support in diagnosis in IBS building maintenance.

- $\quad$ Building a CMMS Expert using BIM in an integrated way is a vital task of IBS building maintenance. Such a system can serve as a core to detect patent or latent defect of an IBS building and provide comprehensive defect diagnosis for supporting the process of decision making.

- Founding intelligent objects capability of the BIM technology of a building can assist improving IBS component diagnosis knowledge integration to reducing risks of defect throughout the IBS building lifetime.

Utilising technology to support maintenance processes and activities can have a positive impact on the delivery of service. Several systems have been developed to facilitate decision making support in diagnosis for IBS building maintenance. However, the efficient practice requires a system that can handle decision making support in diagnosis in an effective way. It is final concluded that CMMS Expert using BIM facilities will enhance the practices of decision making support in diagnosis.

\section{Acknowledgement}

This research is supported by Newton Fund Institutional Links (ID: 172726659), from the British Council and Institute of Research Management \& Monitoring (IPPP) (grant no: IF009-2015), from the University of Malaya.

\section{References}

1. Abreu, J., Martins, P. V., Fernandes, S., Zacarias, M. Business Processes Improvement on Maintenance Management. Procedia Technology, 9(2013), 320330

2. Hamzah, S., Kobayashi, K. Utilising Mid-Long Term Maintenance Management Policy for Sustainable Maintenance of Infrastructure Facilities. Procedia Environmental Sciences, 17(2013), 478-484

3. Ismail, Z. System development toward effective maintenance management practices. Built Environment Project and Asset Management, 4(4), 406-422 (2014)

4. Hamid, Z. A., Kamar, K. A. M., Zain, M. Z. M., Ghani, M. K., Rahim, A. H. A. Industrialised Building System (IBS) in Malaysia: The Current State and R \& D Initiatives. Malaysian Construction Research Journal, (MCRJ), 1(2), 1-11 (2008)

5. Gajzler, M. The Support of Building Management in the Aspect of Technical Maintenance. Procedia Engineering, 54(2013), 615-624

6. Anumba, C. J., Baugh, C., Khalfan, M. M. Organisational Structures to Support Concurrent
Engineering in Construction. Industrial Management \& Data Systems, 102(5), 260-270 (2002)

7. Nawi, M. N. M., Salleh, N. A., Anuar, H. S. A Review Study of Maintenance and Management Issues in IBS Commercial Building. International Journal of Computer Informatics \& Technological Engineering, 1(1), 42-46 (2014)

8. Girmscheid, G., Rinas, T. Business Design Modeling for Industrialization in Construction: Cooperative Approach. Journal of Architectural Engineering, 18(2012), 164-175

9. Wood, B. Maintenance Integrated Design and Manufacture of Buildings: Toward a Sustainable Model. Journal of Architectural Engineering, 18(2012), 192-197

10. Singh, V., Gu, N., Wang, X. A Theoretical Framework of a BIM-Based Multi-Disciplinary Collaboration Platform. Automation in Construction, 20(2), 134-144 (2011)

11. Zahrizan, Z., Ali, N. M., Haron, A. T., MarshallPonting, A., Hamid, Z. A. Exploring the Adoption of Building Information Modelling (BIM) in the Malaysian Construction Industry: A Qualitative Approach. International Journal of Research in Engineering and Technology, 2(8), 384-395 (2013)

12. Ruiz, P. A. P., Kamsu-Foguem, B., Noyes, D. Knowledge Reuse Integrating the Collaboration from Experts in Industrial Maintenance Management. Knowledge-Based Systems, 50(2013), 171-186

13. Kamsu-Foguem, B., Noyes, D. Graph-Based Reasoning in Collaborative Knowledge Management for Industrial Maintenance. Computers in Industry, 64(2013), 998-1013

14. Nawari, N. O. BIM Standard in Off-Site Construction. Journal of Architectural Engineering, 18(2), 107-113 (2012)

15. Cheng, J. C. P., Ma, L. Y. H. A BIM-based System for Demolition and Renovation Waste Estimation and Planning. Waste Management, 33(2013), 15391551

16. Mahdjoubi, L., Moobela, C., Laing, R. Providing Real-Estate Services through the Integration of 3D Laser Scanning and Building Information Modelling. Computers in Industry, 64(2013), 1272-1281

17. Irizarry, J., Karan, E. P., Jalaei, F. Integrating BIM and GIS to Improve the Visual Monitoring of Construction Supply Chain Management. Automation in Construction, 31(2013), 241-254

18. Marzouk, M., Abdelaty, A. BIM-based Framework for Managing Performance of Subway Stations. Automation in Construction, 41(2014), 70-77

19. Love, P. E. D., Matthews, J., Simpson, I., Hill, A., Olatunji, O. A. A Benefits Realization Management Building Information Modeling Framework for Asset Owners. Automation in Construction, 37(2014), 1-10

20. Love, P. E. D., Simpson, I., Hill, A., Standing, C. From Justification to Evaluation: Building Information Modeling for Asset Owners. Automation in Construction, 35(2013), 208-216

21. Miettinen, R., Paavola, S. Beyond the BIM Utopia: Approaches to the Development and Implementation 
of Building Information Modeling. Automation in Construction, 43(2014), 84-91

22. Volk, R., Stengel, J., Schultmann, F. Building Information Modeling (BIM) for Existing Buildings - Literature Review and Future Needs. Automation in Construction, 38(2014), 109-127

23. Rashidi, M., Lemass, B. A Decision Support Methodology for Remediation Planning of Concrete Bridges. KICEM Journal of Construction Engineering and Project Management, 1(2), 1-10 (2011)

24. Yunus, R., Yang, J. Critical Sustainability Factors in Industrialised Building Systems. Construction Innovation, 12(4), 447-463 (2012)

25. Nawi, M. N. M., Haron, A. T., Hamid, Z. A., Kamar, K. A. M., Baharuddin, Y. Improving Integrated Practice through Building Information ModellingIntegrated Project Delivery (BIM-IPD) for Malaysian Industrialised Building Systems (IBS) Construction Projects. Malaysia Construction Research Journal (MCRJ), 15(2),1-15 (2014)

26. Wang, Y., Wang, X., Wang, J., Yung, P., Jun, G. Engagement of Facilities Management in Design Stage through BIM: Framework and a Case Study. Advances in Civil Engineering, 2013(2013), 1-8

27. Ismail, Z., Mutalib, A. A., Hamzah, N. Case Study to Analyse Problems and Issues in IBS Building Maintenance. International Journal of Applied Engineering Research, 11(1), 226-232 (2016) 